\title{
Risk factors associated with intracranial hemorrhage in neonates with persistent pulmonary hypertension on ECMO
}

\author{
Sule Doymaz ${ }^{1,2^{*}}$, Marcia Zinger ${ }^{1}$ and Todd Sweberg ${ }^{1}$
}

\begin{abstract}
Background: Up to $40 \%$ of infants with persistent pulmonary hypertension (PPHN) remains refractory to conventional therapies, and extracorporeal membrane oxygenation (ECMO) is offered as an effective support for this group. However, ECMO is a highly invasive and risky procedure with devastating complications such as intracranial hemorrhage $(\mathrm{ICH})$. In this study, we aimed to determine the risk factors for ICH in infants with PPHN.

Methods: A case-control study of patients admitted to the pediatric intensive care unit (PICU) with PPHN requiring ECMO support was conducted. The study was carried out at a 25-bed PICU in large urban tertiary care children's hospital. A total number of 32 subjects were studied. Patients with and without ICH during ECMO were evaluated for activated clotting time (ACT), heparin dosing, platelet count, coagulation profile such as activated partial thromboplastin time (aPTT), prothrombin time (PT), international normalized ratio (INR), fibrinogen level, vital signs including heart rate and mean arterial pressure (MAP), transfusion history, gestational age, and severity of pre-ECMO illness as possible risk factors.

Results: Low fibrinogen level $(115 \pm 13 \mathrm{mg} / \mathrm{dl})$ and low platelet counts $(37.4 \pm 18.3$ Thousand/ $\mu$ l) were associated with higher incidence of ICH ( $p=0.009$ and $p=0.005$, respectively). Elevated MAP $(69 \pm 4.34 \mathrm{mmHg})$ was also noticed in $\mathrm{ICH}$ patients $(p=0.006)$.

Conclusions: Results demonstrated that low fibrinogen level and low platelet count were associated with $\mathrm{ICH}$ in PPHN patients on ECMO. While on ECMO support, maintaining fibrinogen and platelet counts within normal ranges seems crucial to prevent ICH in PPHN patients. This is the first report identifying low fibrinogen level among the risk factors for $\mathrm{ICH}$ in infants with PPHN on ECMO support.
\end{abstract}

Keywords: Intracranial hemorrhage, Neonates, ECMO, Pulmonary, Hypertension

\section{Background}

Extracorporeal membrane oxygenation (ECMO) is an advanced support for patients who fail to respond to conventional therapy [1]. With ECMO support, survival rate has been improved for many life-threatening conditions related to respiratory failure over the years $[1,2]$. The overall survival rate for neonates with respiratory failure have been treated with ECMO was reported to be $79.7 \%$, and the survival rate for persistent pulmonary hypertension (PPHN) patients was reported as 79.4\% [2].

\footnotetext{
*Correspondence: sule.doymaz@downstate.edu

'Pediatric Critical Care Division, Cohen Children's Medical Center of New York, New Hyde Park, NY 11040, USA

${ }^{2}$ Department of Pediatrics and Division of Pediatric Intensive Care Unit, SUNY DOWNSTATE Medical Center, 450 Clarkson Ave, Brooklyn, NY 11203, USA
}

Occurring in 1.9 in 1,000 live births, PPHN is a condition where there is a failure of normal circulatory transition after birth [3]. As a result, the normal drop in pulmonary vascular resistance (PVR) fails to take place after birth leading to hypoxemia [4]. Both non-invasive and invasive mechanical ventilation as well as inhaled nitric oxide are used to provide adequate tissue oxygenation until PVR drops and normal circulatory dynamics are established [5]. Despite improvements in these conventional therapies, up to $40 \%$ of infants with PPHN remain refractory to therapy. For this group of patients, ECMO has been offered as an effective therapy since its adoption in the 1980s $[3,5]$.

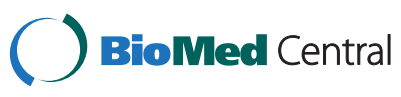

(c) 2015 Doymaz et al.; licensee BioMed Central. This is an Open Access article distributed under the terms of the Creative Commons Attribution License (http://creativecommons.org/licenses/by/4.0), which permits unrestricted use, distribution, and reproduction in any medium, provided the original work is properly credited. The Creative Commons Public Domain Dedication waiver (http://creativecommons.org/publicdomain/zero/1.0/) applies to the data made available in this article, unless otherwise stated. 
Despite its success, ECMO remains a highly invasive and risky procedure. In the neonatal population, one of the most devastating complications is intracranial hemorrhage (ICH) $[1,6]$. The need for anticoagulation in combination with the immature neonatal brain parenchyma makes the risk of ICH particularly high in this population. In previous studies, intracranial complications were reported as $25 \%$ to $50 \%$ with a survival rate of $43 \%$ [6].

Tubings and membranes of ECMO circuits are risk factors for the activation of the coagulation system [7]. Unfractionated heparin (UFH) is used in to prevent clots in ECMO circuit and the complications related to clot formation in patients. It is crucial to monitor the level of anticoagulation therapy closely to prevent the complications such as ICH as well as to track biochemical parameters such as activated partial thromboplastin time (aPTT), activated clotting time (ACT), and anti-factor $\mathrm{Xa}$ (anti-Xa) activity [7].

Relying on a single method has drawbacks. For example, PTT is used to determine the deficiencies of various coagulation factors and to monitor the heparin treatment. Prolonged PTT could be caused by many factors including liver diseases, deficiencies in coagulation factors and vitamin $\mathrm{K}$, disseminated intravascular coagulation, etc.

Activated coagulation time (ACT) test is another method that is used for monitoring heparin treatment and is used with fresh blood at the bedside. In experienced hands, ACT produces reliable results. However, preanalytical conditions such as the presence of hemolysis and suboptimal specimens might adversely affect the outcome.

A chromogenic assay named anti-Xa is utilized in quantifying UFH level. Factors such as free hemoglobin, bilirubin, and triglycerides in plasma may decrease the sensitivity of anti-Xa test [7].

Taken together, there is a need for a better delineation of the factors causing bleeding complications during the ECMO support [1]. The objective of the present study was to investigate the occurrence of $\mathrm{ICH}$ and to identify risk factors in neonates with PPHN.

\section{Methods}

We retrospectively reviewed charts of infants between 1997 and 2010 and included all infants with PPHN diagnoses who required ECMO support. Infants who received ECMO support for all other pathologies such as meconium aspiration syndrome, congenital diaphragmatic hernia, acute respiratory distress syndrome, sepsis/pneumonia, or cardiac pathology were excluded. The reason for the exclusions was to study a uniform group of subjects. The aim was to reach a better comparison between patients with the same pathology. Different pathologies may affect coagulation system differently such as sepsis where patients may be more prone to develop disseminated intravascular coagulation or to bleeding post cardiac surgery. It is hoped that the uniformity of the subject might empower the analysis and the conclusion drawn from the study.

Data collection included: demographic information on age, sex, birth weight, ethnicity, type of ECMO, and duration on ECMO. Hourly ACT levels and heparin infusion doses for the first $12 \mathrm{~h}$ of ECMO and maximum ACT levels and heparin infusion doses for 5 days on ECMO for both groups were also collected. Coagulation profile for a-PTT, prothrombin time (PT), international normalized ratio (INR), and fibrinogen and platelet levels were analyzed. In our unit, the anticoagulation protocol for ECMO dictates that unfractionated heparin be used and infusion is given directly to ECMO circuit via an infusion port located before the bladder. The heparin infusion rate is determined by patient's weight (in $\mathrm{kg}$ ) $\times$ desired unit $/ \mathrm{kg} / \mathrm{h}$ (concentration of drip: 50 units $/ \mathrm{ml}$ ).

We check ACT hourly for a target value of 200-225 s. Target ACT values were adopted from Extracorporeal Life Support Organization (ELSO) guidelines [8]. All ACT levels are obtained from the ACT port located on the pre-membrane oxygenator diamond. PTT is monitored every $6 \mathrm{~h}$ during ECMO. Our target PTT level is $80-110$ s. If ACT level is greater than the target range, we decrease the heparin infusion by $5-15$ units/h. If the ACT is $20-25 \mathrm{~s}$ below the lower end of the target level or PTT is $<65 \mathrm{~s}$, a heparin bolus of 20 units $/ \mathrm{kg}$ is given and infusion is increased by $5-15$ units/h. If PTT level is $>140,10 \mathrm{ml} / \mathrm{kg}$ of fresh frozen plasma (FFP) is given. Platelet levels are checked every $6 \mathrm{~h}$ to a target value of $>100,000$, if less; platelet transfusion of $10 \mathrm{ml} / \mathrm{kg}$ is given. Fibrinogen level is checked every $12 \mathrm{~h}$ to a target value of $>100 \mathrm{mg} / \mathrm{dL}$. If the level is lower than the target value, cryoprecipitate is given to the patient. Heparin drip is increased by $5-15$ units/h during platelet infusion and reduced to previous rate once the platelet infusion is completed.

Data were also collected for heart rate, mean arterial pressure (MAP) changes as well as minimum and maximum $\mathrm{pH}, \mathrm{PCO}_{2}, \mathrm{PaO}_{2}$, and lactate levels. All infants were placed on ECMO support through neck cannulation. Decision for VA ECMO was based on patient's clinical status, persistent and significant acidosis, higher level of respiratory support and hypoxemia, or signs of poor end organ perfusion. The hypoxia is described as having oxygenation index $\geq 40$ for $\geq 4$ h or persistently high oxygenation index for more than $12 \mathrm{~h}$ or $\mathrm{PaO}_{2} \leq 40$ despite maximum medical management.

Management of ICH on ECMO in our institution: Patients are decannulated if the intracranial hemorrhage is associated with profound clinical deterioration. If they remain asymptomatic, we maintain the lowest ACT possible 
(180-200) and repeat head ultrasound (HUS) more frequently. If ICH progresses, decannulation is considered as soon as full mechanical ventilator support can be achieved even if the settings are very high.

All infants had HUS evaluation prior ECMO cannulation. Baseline head US evaluations were negative for ICH before initiation of ECMO support. Daily HUS study was obtained to assess intracranial bleeding during ECMO. All ICH cases were diagnosed by HUS, and no CT scan were performed. All patients in the study were placed on prophylactic antibiotics. There was no mortality in our study population.

For statistical analyses, two-sample $t$ test and chi-square tests were used and the null hypothesis was rejected at a $p \leq 0.05$. In all statistical analyses, Minitab $^{\mathrm{R}}$ (State College, PA 16801, USA) Program was utilized.

The study received approval from IRB of North Shore LIJ Health System.

\section{Results}

A total number of 32 subjects were included in the study. The primary reason for initiation of ECMO in all patients was the persistent hypoxia unresponsive to conventional therapy. Eleven patients were identified to have $\mathrm{ICH}$ by routine daily ultrasound, and 21 patients were without ICH. Demographic data is shown in Table 1. Mean duration of ECMO in hours was not significantly longer in the $\mathrm{ICH}$ group compared to the non- $\mathrm{ICH}$ group $(p=0.680)$. All factors and variables were measured and compared before ICH occurrence on both groups. The data on the maximum ACT levels and heparin infusion doses for $120 \mathrm{~h}$ on ECMO are shown in Table 2. We presented hourly ACT levels and heparin infusion doses for the two groups during the first $12 \mathrm{~h}$ on ECMO and found no statistical significance between the two groups (Table 2).

However, comparison of coagulation profiles indicated that the mean minimum platelet count and fibrinogen levels were significantly lower in the ICH group as demonstrated in Table 3 ( $p=0.005$ and 0.009 , respectively). We found no statistical difference between a PTT, PT and INR values between the groups (Table 3). Similarly,

Table 1 Patients demographic data

\begin{tabular}{llll}
\hline & ICH & No ICH & $\boldsymbol{p}$ values \\
\hline Total number of patients: 32 & $11(34 \%)$ & $21(66 \%)$ & \\
$\begin{array}{l}\text { Gestational age in weeks } \\
\text { (mean } \pm \text { SD) }\end{array}$ & $38.1 \pm 1.2$ & $38.3 \pm 1.8$ & 0.743 \\
Gender (F/M) & $4 / 7$ & $5 / 16$ & 0.453 \\
Weight in $\mathrm{kg}$ (mean \pm SD) & $3.3 \pm 0.2$ & $3.4 \pm 0.6$ & 0.602 \\
$\begin{array}{l}\text { Type of ECMO (WNA) } \\
\begin{array}{l}\text { Duration of ECMO in hour } \\
\text { (mean } \pm \text { SD) }\end{array}\end{array}$ & $4 / 7$ & $9 / 12$ & 0.722 \\
\hline
\end{tabular}

mean volumes of platelet, fresh frozen plasma and cryoprecipitate transfusions for both groups were not significantly different between two groups (Table 3 ). Mean arterial pressure measurements were higher in the $\mathrm{ICH}$ group compared to the non-ICH group $(69.36 \pm 4.34$ vs. $64.19 \pm 4.86 \mathrm{mmHg}$ with a $p=0.006$ ) (Table 4). Minimum and maximum heart rate measurements were not statistically different between the two groups (Table 4). Similarly, the minimum $\mathrm{pH}$ values, maximum lactate levels, highest $\mathrm{PaCO}_{2}$, and lowest $\mathrm{PaO}_{2}$ in two groups did not differ significantly (Table 4).

\section{Discussion}

Our results showed that low fibrinogen and platelet levels as well as higher MAP were associated with developing ICH. In this report, low fibrinogen level for the first time in the literature was identified as a risk factor for ICH for PPHN patients. Previous studies indicated the risk factors for developing $\mathrm{ICH}$ as low platelet counts, difficulty in maintaining platelet counts and ACT levels in normal range with frequent platelet transfusions and frequent adjustments to the heparin drip rate [9-11]. In our study, both groups had similar mean hourly ACT levels as well as heparin infusion doses during the first $12 \mathrm{~h}$ on ECMO. Additionally, the maximum $\mathrm{ACT}$ and heparin infusion doses per day for the first 5 days were similar. Mean volumes of platelet transfusions between the two groups were not statistically significant $(p=0.812)$.

Significantly, however, lower fibrinogen levels in the $\mathrm{ICH}$ group compared to the non- $\mathrm{ICH}$ group were noticed $(p=0.009)$. In one study, Kasirajan pointed to lower fibrinogen levels in adult patients with $\mathrm{ICH}$ during ECMO; nevertheless, the results did not reach to a statistical significance. In that study, there was a strong correlation between thrombocytopenia and risk of $\mathrm{ICH}$ [12]. To our knowledge, this is the first report to show low fibrinogen levels as a risk factor in infants for $\mathrm{ICH}$ on ECMO support. Consumption of coagulation factors by the ECMO circuit has been known to occur, and the consequent deposition of fibrin which might cause the transfer of the patient to newly primed circuit has been reported $[7,13]$.

In a previous study, metabolic acidosis, bicarbonate use or inotrope/vasopressor requirement, cardiopulmonary resuscitation, or a left ventricular-assisted device before initiation of extracorporeal life support were identified as risk factors for developing neurological complications on ECMO [14]. In our study, minimum $\mathrm{pH}$ levels for both groups were similar during the course of ECMO support and highest lactate levels were not significantly different in both groups. We identified that increased MAP were related to ICH $(p=0.006)$. One can postulate that a lower target MAP may help prevent 
Table 2 Maximum daily ACT values and maximum heparin infusion doses for each day*

\begin{tabular}{lllllll}
\hline & Group & Day 1 & Day 2 & Day 3 & Day 4 & Day 5 \\
\hline ACT in seconds (mean \pm SD) & ICH & $318.3 \pm 54.8$ & $260.8 \pm 57.0$ & $259.3 \pm 62.2$ & $264.8 \pm 58.5$ & $271.4 \pm 57.3$ \\
& No ICH & $313.7 \pm 61.2$ & $259.3 \pm 29.0$ & $252.2 \pm 42.1$ & $257.0 \pm 33.2$ & $255.6 \pm 45.9$ \\
Max. heparin (mean \pm SD) & ICH & $32.1 \pm 11.9$ & $34.0 \pm 11.4$ & $40.2 \pm 16.3$ & $39.8 \pm 11.3$ & $37.8 \pm 12.6$ \\
& No ICH & $36.2 \pm 11.8$ & $37.6 \pm 9.08$ & $39.95 \pm 7.93$ & $43.5 \pm 12.5$ & $38.4 \pm 13.9$ \\
\hline
\end{tabular}

${ }^{*} p$ values for maximum daily ACT values and maximum heparin infusion doses for each day were not statistically significant.

$\mathrm{ICH}$, as long as an adequate tissue perfusion is maintained.

Systemic arterial hypertension can result in increasing cerebral blood flow in hypoxic newborns if autoregulatory mechanisms decreased or lost. An abnormality in cerebral blood flow is a risk factor for ICH in newborn. One experimental animal study showed that systemic hypertension resulted in germinal matrix hemorrhage [15].

Gestational age was reported to be the most significant predictor of $\mathrm{ICH}$, especially if it is less than 34 weeks [16]. Our study did not support that finding; mean gestational age was $38.1 \pm 1.2$ weeks in the $\mathrm{ICH}$ group vs. $38.3 \pm 1.8$ weeks for the non-ICH group (Table 1 ). Hervey-Jumper and colleagues [17] reported that infants less than 30 days of age and requiring ECMO support for cardiac etiology were more prone to have $\mathrm{ICH}$ on ECMO. In our study, all patients were less than 30 days of age with a mean age of 2.3 days in both groups at the start of ECMO, and not differing significantly between study groups $(p=0.947)$.

Previously, sepsis as a primary diagnosis was indicated to form an increased risk for $\mathrm{ICH}$ in infants compared to non-septic infants, and among septic infants, timing of ICH was reported at less than $72 \mathrm{~h}$ on ECMO [18]. In the current study, none of our patients had sepsis, and consequently, sepsis was not a factor for this study.

Table 3 Data related to coagulation profiles

\begin{tabular}{|c|c|c|c|}
\hline & $\begin{array}{l}\mathrm{ICH} \\
(\text { mean } \pm \mathrm{SD})\end{array}$ & $\begin{array}{l}\text { No ICH } \\
(\text { mean } \pm \text { SD) }\end{array}$ & $p$ values \\
\hline Min. platelet (Thousand/ul) & $37.4 \pm 18.3$ & $60.4 \pm 23.3$ & 0.005 \\
\hline Max. platelet (Thousand/ $\mu$ l) & $116.4 \pm 18.9$ & $140.7 \pm 35.4$ & 0.017 \\
\hline Min. PTT (s) & $50.4 \pm 13.9$ & $60.6 \pm 19.8$ & 0.101 \\
\hline Max. PTT (s) & $165 \pm 48.7$ & $173 \pm 33.9$ & 0.661 \\
\hline Min. PT (s) & $13.18 \pm 1.33$ & $13.38 \pm 1.96$ & 0.737 \\
\hline Max. PT (s) & $23.09 \pm 7.23$ & $20.24 \pm 6.54$ & 0.288 \\
\hline Min. fibrinogen (mg/dl) & $115 \pm 43.8$ & $175 \pm 74.8$ & 0.009 \\
\hline Max. fibrinogen (mg/dl) & $326 \pm 119$ & $336 \pm 83.9$ & 0.809 \\
\hline Min. INR & $1.14 \pm 0.93$ & $1.13 \pm 0.13$ & 0.714 \\
\hline Max. INR & $1.94 \pm 0.67$ & $1.61 \pm 1.50$ & 0.171 \\
\hline Platelet V. (ml) & $400.90 \pm 314.80$ & $434.30 \pm 407.19$ & 0.812 \\
\hline FFP V. (ml) & $107.60 \pm 89.20$ & $86.80 \pm 44.15$ & 0.380 \\
\hline Cryoprecipitate V. (ml) & $15.45 \pm 20.18$ & $7.85 \pm 21.5$ & 0.346 \\
\hline
\end{tabular}

In our study, the incidence of ICH (34\%) is relatively higher compared with ELSO registry data (11\%) [8]. Obviously, the one explanation would be the difference in the study group reported here and the ELSO registry patients. One might argue that we report from a subpopulation of the patients undergoing ECMO support procedure and the overall incidence would closely follow the national data.

In recent studies, the search for a better test for monitoring the coagulation status of ECMO patients addressed $[19,20]$. Anti-Xa test has been indicated as a better correlate for heparin dosing compared to ACT and aPTT tests. Also, antithrombin III test and use of thromboelastography have been mentioned. However, the studies are reported from relatively small group of patients, and further detailed investigations with additional parameters including anti-Xa, antithrombin III, fibrin degradation products, or d-dimers might be useful to establish the utility of these measurements.

One limitation of our study was the small number of patient population with 32 subjects. Furthermore, we reviewed the patient's data retrospectively. However, it should be pointed out that our data obtained from relatively homogenous group of patients and the study covers a period of 14 years at a high volume reference PICU in a large university medical center, indicating the

Table 4 Arterial blood gas analysis and changes in vital signs

\begin{tabular}{llll}
\hline & $\begin{array}{l}\text { ICH } \\
\text { (mean } \pm \text { SD) }\end{array}$ & $\begin{array}{l}\text { No ICH } \\
\text { (mean } \pm \text { SD) }\end{array}$ & p values \\
\hline Lowest pH & $7.22 \pm 0.12$ & $7.24 \pm 0.13$ & 0.701 \\
Highest pH & $7.48 \pm 0.02$ & $7.49 \pm 0.06$ & 0.818 \\
Lowest $\mathrm{PaCO}_{2}(\mathrm{mmHg})$ & $32.73 \pm 7.02$ & $30.10 \pm 6.6$ & 0.318 \\
Highest $\mathrm{PaCO}_{2}(\mathrm{mmHg})$ & $65.90 \pm 27.9$ & $61 \pm 17.5$ & 0.601 \\
Lowest PaO $(\mathrm{mmHg})$ & $52.2 \pm 16.7$ & $45.6 \pm 16.2$ & 0.298 \\
Highest $\mathrm{PaO}_{2}(\mathrm{mmHg})$ & $189.7 \pm 61.7$ & $179.4 \pm 83.9$ & 0.695 \\
Low lactate $(\mathrm{mmol} / \mathrm{l})$ & $1.143 \pm 0.51$ & $1.04 \pm 0.59$ & 0.704 \\
High lactate $(\mathrm{mmol} / \mathrm{l})$ & $5.76 \pm 4.41$ & $3.75 \pm 3.91$ & 0.335 \\
Min. HR $(\mathrm{bpm})$ & $105.6 \pm 24.2$ & $101.7 \pm 14.5$ & 0.626 \\
Max. HR $(\mathrm{bpm})$ & $169.2 \pm 20.9$ & $176.9 \pm 15.7$ & 0.301 \\
Min. MAP $(\mathrm{mmHg})$ & $40.09 \pm 6.85$ & $36.52 \pm 5.01$ & 0.148 \\
Max. MAP $(\mathrm{mmHg})$ & $69.36 \pm 4.34$ & $64.19 \pm 4.86$ & 0.006 \\
\hline
\end{tabular}


relative scarcity of patients with similar demographics for this type of analysis. Nevertheless, prospective multicenter studies with a larger patient size might provide a stronger support to the present findings, and the inclusion of larger number of patients on a prospective investigation would eliminate some of the drawbacks that might be resulting from limits on patient number.

\section{Conclusions}

Despite the limitations, our study demonstrated that several factors such as low fibrinogen level, low platelet counts, and high MAP might be associated in development of ICH on ECMO patients. These associations are significant, and some such as low fibrinogen levels are reported for the first time in the literature.

\begin{abstract}
Abbreviations
ICH: Intracranial hemorrhage; PPHN: Persistent pulmonary hypertension; ECMO: Extra corporeal membrane oxygenation; MAP: Mean arterial pressure; ACT: Activated clotting time; PT: Prothrombin time; aPTT: Activated partial thromboplastin time; INR: International normalized ratio; HUS: Head ultrasound; CT: Computerized tomography; SD: Standard deviation; FFP: Fresh frozen plasma; PVR: Pulmonary vascular resistance; ELSO: Extracorporeal Life Support Organization.
\end{abstract}

\section{Competing interests}

The authors declare that they have no competing interests.

\section{Authors' contributions}

SD and TS participated in the conception and design, performed the analysis and interpretation, and drafted the manuscript and intellectual content. SD and MZ carried out the data collection and methods. All authors read and approved the final manuscript.

\section{Acknowledgements}

We thank to Nancy B. Riebling for the statistical analysis of the data.

Received: 3 July 2014 Accepted: 5 January 2015

Published online: 11 February 2015

\section{References}

1. Rehder KJ, Turner DA, Cheifetz IM. Extracorporeal membrane oxygenation for neonatal and pediatric respiratory failure: an evidence-based review of the past decade (2002-2012). Pediatr Crit Care Med. 2013;14(9):851-61.

2. Keckler SJ, Laituri CA, Ostlie DJ, St Peter SD. A review of venovenous and venoarterial extracorporeal membrane oxygenation in neonates and children. Eur J Pediatr Surg. 2010;20(1):1-4.

3. Walsh-Sukys MC, Tyson JE, Wright LL, Bauer CR, Korones SB, Stevenson DK, et al. Persistent pulmonary hypertension of the newborn in the era before nitric oxide: practice variation and outcomes. Pediatrics. 2000;105(1 Pt 1):14-20.

4. Delaney $\mathrm{C}$, Cornfield DN. Risk factors for persistent pulmonary hypertension of the newborn. Pulm Circ. 2012;2(1):15-20.

5. Neonatal Inhaled Nitric Oxide Study G. Inhaled nitric oxide in full-term and nearly full-term infants with hypoxic respiratory failure. N Engl J Med. 1997:336(9):597-604.

6. Hardart GE, Fackler JC. Predictors of intracranial hemorrhage during neonatal extracorporeal membrane oxygenation. J Pediatr. 1999:134(2):156-9.

7. Khaja WA, Bilen O, Lukner RB, Edwards R, Teruya J. Evaluation of heparin assay for coagulation management in newborns undergoing ECMO. Am J Clin Pathol. 2010;134(6):950-4.

8. ELSO. Extracorporeal Life Support Organization guidelines for ECMO centers. 2014. http://www.elso.org/Resources/Guidelines.aspx

9. Zwischenberger JB, Nguyen TT, Upp Jr JR, Bush PE, Cox Jr CS, Delosh T, et al. Complications of neonatal extracorporeal membrane oxygenation.
Collective experience from the Extracorporeal Life Support Organization. J Thorac Cardiovasc Surg. 1994;107(3):838-48. discussion 848-839.

10. Stallion A, Cofer BR, Rafferty JA, Ziegler MM, Ryckman FC. The significant relationship between platelet count and haemorrhagic complications on ECMO. Perfusion. 1994;9(4):265-9.

11. Hirthler MA, Blackwell E, Abbe D, Doe-Chapman R, LeClair SC, Goldthorn J, et al. Coagulation parameter instability as an early predictor of intracranial hemorrhage during extracorporeal membrane oxygenation. J Pediatr Surg. 1992;27(1):40-3.

12. Kasirajan V, Smedira NG, McCarthy JF, Casselman F, Boparai N, McCarthy PM. Risk factors for intracranial hemorrhage in adults on extracorporeal membrane oxygenation. Eur J Cardiothorac Surg. 1999;15(4):508-14.

13. Friedman DF, Montenegro LM. Extracorporeal membrane oxygenation and cardiopulmonary bypass (Chapter 17). In: Hillyer CD, Strauss RG, Luban NLC, editors. 'Handbook of Pediatric Transfusion Medicine'. San Diego: Elsevier Academic Press; 2004. p. 181-9.

14. Dela Cruz TV, Stewart DL, Winston SJ, Weatherman KS, Phelps JL, Mendoza JC. Risk factors for intracranial hemorrhage in the extracorporeal membrane oxygenation patient. J Perinatol. 1997;17(1):18-23.

15. Pasternak JF, Groothuis DR. Autoregulation of cerebral blood flow in the newborn beagle puppy. Biol Neonate. 1985;48(2):100-9.

16. Karimova A, Brown K, Ridout D, Beierlein W, Cassidy J, Smith J, et al. Neonatal extracorporeal membrane oxygenation: practice patterns and predictors of outcome in the UK. Arch Dis Child Fetal Neonatal Ed. 2009;94(2):F129-32.

17. Hervey-Jumper SL, Annich GM, Yancon AR, Garton HJ, Muraszko KM Maher CO. Neurological complications of extracorporeal membrane oxygenation in children. J Neurosurg Pediatr. 2011;7(4):338-44.

18. Cengiz P, Seidel K, Rycus PT, Brogan TV, Roberts JS. Central nervous system complications during pediatric extracorporeal life support: incidence and risk factors. Crit Care Med. 2005;33(12):2817-24.

19. Nguyen T, Musick M, Teruya J. Anticoagulation monitoring during extracorporeal membrane oxygenation: is anti-factor Xa assay (heparin level) a better test?*. Pediatr Crit Care Med. 2014;15(2):178-9.

20. Bembea MM, Annich G, Rycus P, Oldenburg G, Berkowitz I, Pronovost P. Variability in anticoagulation management of patients on extracorporeal membrane oxygenation: an international survey. Pediatr Crit Care Med. 2013;14(2):e77-84.

\section{Submit your next manuscript to BioMed Central and take full advantage of:}

- Convenient online submission

- Thorough peer review

- No space constraints or color figure charges

- Immediate publication on acceptance

- Inclusion in PubMed, CAS, Scopus and Google Scholar

- Research which is freely available for redistribution 